\title{
Narrativas e processo de reconstrução do significado no luto
}

\author{
Narratives and reconstruction of meaning in the \\ bereavement process
}

\begin{abstract}
RESUMO
O artigo analisa o processo de luto a partir da teoria da reconstrução do significado no luto. Parte de uma pesquisa qualitativa que investigou as narrativas de luto, com 12 pessoas que perderam um membro familiar na vida adulta. Para a coleta de dados utilizou-se o genograma e a entrevista com roteiro semiestruturado. A organização e integração dos dados foram feitos através da codificação da Teoria Fundamentada e do software Atlasti 5.0. Na análise de dados, seis categorias conceituais sustentaram as narrativas: as que versam sobre o relacionamento afetivo no ciclo vital adulto, a perda deste, o enlutamento, a crise, o enfrentamento e as mudanças. As narrativas indicam que o processo de luto implica a busca por significados no relacionamento com a pessoa que morreu e também por atribuir significado às novas experiências e situações vivenciadas a partir da perda. Conclui-se que o processo de transformação do mundo presumido se dá a partir de duas direções: na manutenção de significados previamente consolidados e na articulação de novos significados e possibilidades identitárias.
\end{abstract}

Palavras-chave: Perda - Narrativa - Processo de luto - Mundo presumido - Reconstrução do significado

\begin{abstract}
This article aims to understand the grief process according to the theory of reconstruction of meaning in bereavement. In order to do so, this study investigated grief narratives. The qualitative study was developed with 12 people who lost a family member in adult life. Data gathering was conducted through genogram and semi-structured interview, while organization and integration of data was made with Grounded Theory codification procedures and with Atlas-ti 5.0 software. The results have shown that six conceptual categories supported the narratives: 1 ) those related to the emotional relationship in the adult life cycle; 2) loss itself, 3) grieving; 4) crisis; 5) coping and 6) changes. These findings indicate that the grief process implies a search for sense in the previous relationship with the person who died also assigning significance to new experiences and situations that occurred as result of the loss. In conclusion, the process of transformation happens in the presumed world, taking place in two simultaneous directions: in the maintenance of previously consolidated senses and in the articulation of new senses and identity possibilities.
\end{abstract}

Keywords: Loss - Narrative - Grief Process - Presumed World - Meaning Reconstruction

* Doutora em Psicologia pela Universidade Federal de Santa Catarina (UFSC). Tem experiência profissional como docente no ensino universitário (Unisul, Univali e Unidavi) e como psicóloga hospitalar no Hospital Universitário da Universidade Federal de Santa Catarina (UFSC). Professora no Departamento de Psicologia desta Universidade. Pesquisadora no grupo de pesquisa 'Psicologia, cultura e saúde mental', da Universidade Federal de Santa Catarina (UFSC). CV: http://lattes.cnpq.br/7745723516398229

* * Pós-Doutora em Psicologia Social pela Universidad Autonôma de Barcelona, Espanha. Doutora em Psicologia Clínica pela Pontifícia Universidade Católica de São Paulo (PUC-SP). Na área da Psicologia Hospitalar, faz parte do corpo docente da Residência Multidisciplinar de Alta Complexidade do Hospital Universitário, da Universidade Federal de Santa Catarina (UFSC). Coordenadora do Programa de Pós-graduação em Psicologia da Universidade Federal de Santa Catarina (UFSC). CV: http://lattes.cnpq. br/4175376265063250 


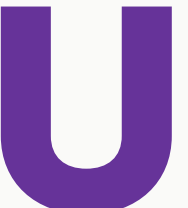

ma situação de luto apresenta-se à medida que a pessoa, família e/ou comunidade se defrontam com a morte e/ou separação de um ente querido ou algo significativo. Especificamente, na língua inglesa, observam-se terminologias para diferenciar a situação de luto (bereavement), a experiência subjetiva de sofrimento (grief) e a demanda de compartilhamento social dessa experiência (mourning). ${ }^{1} \mathrm{~A}$ importância da distinção das terminologias tem sido apontada por Walter (1996 e 1997), quando discute a secularização da morte e da situação de luto na sociedade inglesa, e a consequente delimitação de um campo de conhecimento - Psicologia do Luto - envolvido na compreensão do pesar e do enlutar-se. Neste artigo, preferencialmente, utilizar-se-á o termo experiência de luto, ao invés de pesar. Assim, será apresentada uma revisão de conceitos sobre essa experiência, a fim de apontar aspectos teóricos e de pesquisa relevantes nesse campo, e que serviram de base para a pesquisa realizada.

No início e metade do século XX, uma das preocupações dos autores foi diferenciar a experiência de luto de outros estados psicológicos. Assim, Freud ${ }^{2}$ distingue a reação depressiva, despertada pela perda objetal, da reação melancólica que caracteriza uma condição psíquica patológica. Bowlby (1961), por sua vez, caracteriza as reações de sofrimento advindas da perda do vínculo como anseio e protesto. Há concepções que tematizam como se dá o processo intrapsíquico e interpessoal de adaptação e resolução de uma experiência de luto. Nesse sentido, observam-se os conceitos de trabalho de luto (Freud, 1917/1974), transição psicossocial (Parkes, 1988), fases de luto (Bowlby, 1961) e modelo do processo dual de luto (Stroebe e Schut, 1999). O debate contemporâneo sobre a experiência de luto enfatiza os padrões comportamentais, principalmente quando o luto normal e o complicado são analisados (Franco, 2010). Assim, é possivel afirmar que a pessoa enlutada pode estar orientada para a manutenção do vínculo com quem morreu - quando está focada no confronto da realidade da perda - e, ao mesmo tempo oscilar, quando concomitantemente desenvolve atividades de reconstrução da identidade (Stroebe e Schut, 1999).

O modelo do processo dual de luto problematiza a ideia de um modelo normativo de sofrimento sustentado na hipótese do desligamento psíquico, trazendo à reflexão o processo de continuidade e transformação do vínculo com a pessoa que morreu, como abordado por Klass, Silvermann e Nickmann (1996), quando refletem sobre a experiência de "vínculos contínuos" no luto. Já Bowlby (1998) e Parkes (2009), quando propõem compreender a redefinição dos modelos operativos internos ou mundo presumido; e Neimeyer (2001), que ressalta o processo de reconstrução da estrutra do sistema de significados. Todos esses autores reconhecem o paradoxo da perda, pioneiramente descrito por Marris (1993) como um processo ambivalente de transformação de concepções e crenças básicas à vida.

Parkes (2009) cunhou a expressão mundo presumido para designar o mundo interno

\footnotetext{
1 Na literatura brasileira, observa-se que Franco (2002 e 2010), pesquisadora brasileira e tradutora dos livros de Colin Parkes - Estudos sobre o Luto na Vida Adulta (1996) e Amor e Perda: raízes do luto e suas complicações (2009) -, traduziu bereavement como luto, grief como pesar e mourning como enlutamento, termos também adotados neste artigo.

2 FREUD, Sigmund. Luto e melancolia. In: Edições Standard Brasileira das Obras Completas de Sigmund Freud: Imago, v. 14, 1974[1917].
} 
percebido como verdadeiro, composto por concepções sobre nós mesmos, nossos pais, nossa capacidade de lidar com o perigo, e cognições que compõem a estrutura complexa, que depende de nosso senso de significado e propósito de vida. Para tanto, neste artigo é debatida a experiência de luto como uma crise de manutenção e transformação do mundo presumido, ao nível cognitivo, interpessoal e social. Tal instância - o mundo presumido - é aqui considerada como organizadora da atenção, do julgamento e do afeto, não apenas de um indivíduo, mas da comunidade relacional, em sentido amplo. Gillies e Neimeyer (2006) salientam que a reconstrução do significado não ocorre somente no caso de uma pessoa em processo de luto, mas entre ela e as pessoas que a cercam, pois as estruturas de significados constituem construções sociais, uma rede de conexões criada a partir dos discursos sociais em torno do mundo em que se vive, e tornam-se reais por meio das ações realizadas no mundo.

Nesse aspecto, a vertente construcionista social contribui com a reflexão sobre os sistemas linguísticos envolvidos na coconstrução da experiência de luto. Wambach (1985) destaca o conceito "processo de luto" como narrativa importante na sociedade contemporânea. Trata-se de uma construção social retroalimentada por profissionais de saúde, enlutados e pesquisadores. Esse processo serve como guia e marcador de tempo para as experiências vividas a partir de uma perda. A mesma autora observou também que as conversações nos grupos de mútua ajuda eram pautadas pelas fases pelas quais o enlutado deve se reconhecer e passar. Ademais, Neimeyer, Klass e Denis (2014) salienta a busca por significados sobre a vida e a morte de quem morreu, bem como o status pós-morte dos enlutados, na comunidade mais ampla envolvida com a perda. Luna e Moré (2013) destacam a atividade linguística e interpretativa desta comunidade, para reconstruir a realidade vivencial após uma perda, o que implica construir narrativas singulares, lidar com significados pré-existentes e construir novos significados.

A perspectiva da reconstrução do significado pode ser observada em Attig (2001), quando considera que o processo de luto envolve uma reaprendizagem do mundo, em termos dos modos de ação de ser no mundo sem a pessoa falecida. Esse autor destaca dois processos: dar significado (meaning making) e encontrar significado (meaning finding). O primeiro processo indica quais significados são atribuídos às ações, experiências e sofrimento. Além disso, eles possibilitam renovar esperanças, reinterpretar aspectos da autonarrativa e autocompreensão, além de reavaliar o lugar no mundo, tendo sempre como base os novos significados criados. Para o autor, esse aspecto direciona o enlutado para a seguinte pergunta: "Quem sou eu agora?". Já o processo de encontrar significados é menos deliberado, implica lidar com significados previamente vivenciados, no contexto de vida antes da ocorrência da perda.

O processo de reconstrução do significado descrito por Attig (2001) é semelhante aos dois padrões comportamentais descritos no modelo do processo dual de luto, pois "encontrar significados" envolve o confronto com a realidade da perda, o que implica manter uma parte dos significados associados ao mundo presumido antes da perda; e "dar significados" envolve afastarse do mundo presumido, pela construção de uma nova realidade. Nesse sentido, o processo de luto segundo a teoria da reconstrução do significado envolve dois padrões: encontrar e dar significado, os quais concomitantemente geram a experiência de transformação do mundo 
presumido. Ademais, esse processo é um artefato social, compartilhado linguisticamente por uma rede relacional, envolvida na construção social de significados. Para desenvolver esse pressuposto, foi realizada pesquisa de doutoramento, que teve como objetivo principal compreender as narrativas, os relacionamentos e os significados que sustentam o processo de reconstrução do significado de pessoas que vivenciaram a perda de um membro familiar na vida adulta. No entanto, neste artigo, serão apresentados os resultados que se referem às narrativas de luto.

A polêmica em torno dos termos narrativa e história é relevante. Tais termos podem ser entendidos como sinônimos, na medida em que Grandesso (2011) posiciona-os no campo da produção de um discurso. Neste estudo, optou-se por dar preferência à palavra narrativa, apesar de a história também ser utilizada. A esse respeito, Grandesso menciona: "entendo por narrativa a organização por meio do discurso, por meio de termos símbolos ou metáforas, de um fluxo de experiência vivida em uma sequência temporal significativa". Nessa direção, uma história expressa a maneira como uma pessoa dá sentido a suas experiências, organizando-as em sequências temporais e coerentes (Grandesso, 2011, p. 199).

Objetiva-se aqui analisar as narrativas de luto, à luz de diferentes estudos sobre a experiência de luto, com ênfase ao processo de luto, a partir da teoria da reconstrução do significado, com enfoque no conceito de mundo presumido de Parkes (1996). Ademais, informase quais narrativas são significativas às pessoas em processo de luto na vida adulta, no cotidiano das relações informais ou formais. Para tanto, sugere-se que as redes de relações e as pessoas em luto protagonizem conversações reconstrutoras do significado, pois estão mutuamente envolvidas na crise de manutenção e descontinuidade de significados, na transformação do mundo presumido como uma experiência coletiva.

\section{Método}

Realizou-se um estudo qualitativo, com delineamento de cunho exploratório e descritivo, que possibilitou a construção de uma postura colaborativa e de respeito frente às vivências e significados advindos d'e uma perda. Nesse sentido, a presente pesquisa se caracteriza, também, por ser de corte transversal, uma vez que as narrativas foram coletadas em determinado momento do tempo (Minayo, 2010).

Participaram do estudo 12 pessoas que perderam um membro familiar por morte. O critério para definir esse número baseou-se no parâmetro utilizado em pesquisas qualitativas, quanto à saturação dos dados (Guest, Bunce e Johnson, 2006). Critérios de inclusão também foram utilizados, sustentados na literatura e considerados pertinentes ao fenômeno problematizado no estudo, como: idade entre 20-59 anos; ter perdido um membro familiar há no mínimo 1 ano e no máximo 5 anos; a circunstância da perda ser repentina ou antecipada; residir em um dos municípios próximos ao contexto da investigação. Constata-se no estudo sistemático da 
literatura entre 2010 e 2014 no Brasil (Luna, 2014) o privilégio de pesquisas sobre a perda de filhos jovens na vida adulta. Esse aspecto evidencia a necessidade de pesquisas que contemplem, além da perda de filho, a do cônjuge, irmãos e pais, pois estas pessoas desempenham relevante papel no status emocional, relacional e social de adultos (Parkes, 2009; Stroebe e Stroebe, 1994; Mccullough e Rutenberg, 1995; Rolland, 1995; Sluzki, 1997; Shapiro, 1994; Walsh e Mcgoldrick, 1998).

A seleção dos participantes contou com a técnica bola de neve (snowball sampling): 10 pessoas foram contatadas por meio da rede de contato profissional da pesquisadora e de 2 pessoas pelos próprios participantes da pesquisa (Denzin e Lincoln, 1980). Para a coleta de dados foram utilizados dois instrumentos principais: o genograma ${ }^{3}$ e o roteiro de entrevista, sendo que a técnica da entrevista qualitativa em profundidade - do tipo semiestruturada - foi o recurso que subsidiou a aplicação destes instrumentos, de acordo com os seguintes princípios éticos: 1) da não diretividade, para não confrontar os entrevistados; 2) especificidade, quando se solicita ao entrevistado que relate situações em que ele vivenciou experiências específicas; 3) abrangência, quando não é definida qualquer área de abrangência em especial, apenas demandando ao entrevistado a narrativa de situações cotidianas e 4) o princípio de dar foco às situações, quando emergem as implicações afetivas e carregadas de valor, para determinar se a experiência possui significância central ou periférica (Olabuénaga, 2009).

O genograma e o roteiro de entrevista foram utilizados, tendo em vista o interesse na construção por parte dos entrevistados de uma "história de perda". Assim, o genograma (Mcgoldrick e Gerson, 1995; Mcgoldrick, Gerson e Petry, 2012) foi confeccionado com o objetivo de evidenciar os estressores do eixo horizontal do ciclo vital da família (como morte, por exemplo), visibilizando os dois critérios de escolha dos participantes da pesquisa: a morte de membros familiares e o intervalo de tempo entre um e cinco anos. As temáticas que compõem o roteiro de entrevista foram oriundas de roteiros que possibilitam gerar dados, principalmente, sobre as reações à morte e o impacto da perda (Moura, 2006; Valentine, 2011).

O estudo foi aprovado pelo Comitê de Ética da Universidade Federal de Santa Catarina, de modo que os procedimentos éticos contemplaram a resolução 466/12 do Conselho Nacional de Saúde, ${ }^{4}$ bem como as orientações gerais e específicas para a conduta ética na pesquisa da experiência de luto (Parkes, 1995). A coleta de dados ${ }^{5}$ ocorreu somente em um encontro de pesquisa, que teve duração em torno de duas horas e meia, tempo computado desde o momento em que a pesquisadora encontrou o participante no local combinado, organizou seu material de trabalho (folhas em branco, lápis, caneta, gravador, roteiro temático, mapa de redes e legenda, caixa de lenço de papel e água), deu sequência aos procedimentos de coleta de dados e despediu-se do participante.

As 12 "histórias de perda", corpus de análise, foram analisadas, organizadas e integradas

3 O genograma é uma representação gráfica multigeracional da família que pressupõe o registro da sua história, do traçado da estrutura familiar e a representação das relações e funcionamentos (Macgoldrick e Gerson, 2001).

4 BRASIL. CONSELHO NACIONAL DE SAÚDE. Resolução no 466, de 12 de dezembro de 2012. Brasília, 2012. Disponível em: http://www.conselho.saude.gov.br/web_comissoes/conep/index.html. Acesso: 04/01/2014.

5 As entrevistas foram realizadas nos anos de 2012, 2013 e 2014. 
por intermédio da utilização do software Atlas ti 5.0 e dos fundamentos da Teoria Fundamentada Empiricamente (Strauss e Corbin, 2008). As ferramentas analíticas principais - as perguntas e comparações - possibilitaram conduzir uma análise conceitual qualitativa, por meio de procedimentos típicos de codificação, como a aberta, a seletiva e a axial. O Atlas.ti 5.0 consiste em um software de análise qualitativa empregado para sistematizar informações, que possibilitou estabelecer conexões e elaborar categorias de análise (Muhr, 2004).

A codificação aberta se deu a partir da leitura atenta de toda a entrevista de pesquisa transcrita, da história de perda produzida pelo participante da pesquisa. Acrescente-se a leitura de linha por linha, frase ou parágrafo inteiro, que possibilitou a seleção dos elementos temáticos. A codificação axial consistiu na congregação dos elementos temáticos, o que possibilitou chegar às narrativas de luto, bem como proceder à codificação seletiva, que integra todos os relatos em seis categorias conceituais, os temas transversais das histórias de perda.

\section{Resultados e discussão}

Tendo em vista o objetivo de compreender as narrativas que sustentam o processo de reconstrução do significado de pessoas que vivenciaram a perda de um membro familiar na vida adulta, primeiramente apresentam-se as características dos participantes que produziram uma história sobre o momento de seu ciclo vital adulto, que se referiu à perda de certo membro familiar, em determinada circunstância, sendo o relato coletado após algum tempo da perda. Em seguida, apresentam-se os resultados obtidos no processo de análise e organização dos dados.

Quatro participantes mulheres encontravam-se no que é denominado como meia idade (35 a 45 anos), três ao final da meia idade (45 a 60 anos) e três no início do ciclo da vida adulta (25 a 35 anos). Tal condição possibilitou observar a produção de 10 histórias de perda, produzidas por mulheres em períodos distintos do ciclo vital adulto. Da mesma forma se deu com os participantes do sexo masculino: dois, sendo um no início do período do ciclo vital adulto e o outro na meia idade.

Houve predomínio do ensino superior (10 participantes), seja completo e/ou incompleto, sendo que a profissão declarada pela maioria não corresponde à ocupação à época das entrevistas. Os participantes com ensino superior incompleto trabalham em áreas paralelas à profissão que almejavam. Dos doze participantes, somente três não empreendem alguma atividade profissional no momento da entrevista, pois referiram dificuldades de manter esta atividade após a vivência da perda. Alguns residem em municípios próximos ao contexto da investigação propriamente dita.

Dentre as 10 mulheres selecionadas, três perderam o filho, três perderam o cônjuge, duas perderam o irmão e uma perdeu o pai. Quanto aos homens, um perdeu o pai e o outro perdeu a irmã. Assim, no conjunto dos 12 participantes selecionados, a construção da história 
ocorreu de forma equitativa, quanto ao membro familiar falecido (três histórias sobre perda de filho, três sobre a perda de irmão, três sobre a perda do cônjuge e três sobre a perda de pai/mãe).

No que diz respeito ao critério referente às circunstâncias da perda, constatou-se a construção de 6 histórias que se referiram à circunstância antecipada (aborto induzido, Parkinson, câncer ou infarto do miocárdio) e 6 histórias sobre evento repentino (acidente de carro, moto, afogamento ou assassinato). Por fim, a partir do critério tempo de perda, a construção das histórias ocorreu em um momento específico; quatro participantes foram entrevistados no quarto ano após a morte; ademais, quatro se encontravam no primeiro ano da perda, três estavam no terceiro, dois no segundo e apenas um se encontrava no primeiro ano, por ocasião da entrevista.

A partir destas características, e por meio do processo de análise conceitual qualitativa, destacam-se seis temas transversais que compõem as histórias de perda: 1) relacionamento; 2) perda; 3) enlutamento; 4) crise; 5) enfrentamento e; 6) mudança. Esses temas são sustentados por narrativas singulares, implicadas no processo de reconstrução do significado. A seguir são apresentadas e debatidas essas narrativas, identificadas a partir do tipo de perda vivenciada, como, por exemplo, quem perdeu filho, cônjuge, pai/mãe ou irmão. A denominação associada a cada caso é, respectivamente, pela letra F, C, P ou I, além do número, concernente à ordem das entrevistas, como F1, C2. As narrativas serão apresentadas a partir dos processos de encontrar e dar significado.

\section{Processo de encontrar significado}

\section{Narrativas sobre o relacionamento}

A primeira categoria conceitual apresenta as experiências dos participantes em torno do relacionamento com a pessoa que morreu, considerando três narrativas singulares: o relacionamento no ciclo vital adulto, as características do vínculo afetivo, e como o falecido era considerado no contexto familiar e social. Neste sentido, os participantes que perderam o cônjuge referem o tempo do relacionamento e o compromisso conjugal no ciclo vital adulto, como $C 2^{6}$ "nós estávamos casados, dia 8 de setembro, agora, faria agora, 22 anos, então foram 20 anos de casados"; A participante $\mathrm{F}^{7}$, que perdeu o filho, narra o processo de escolha do nome

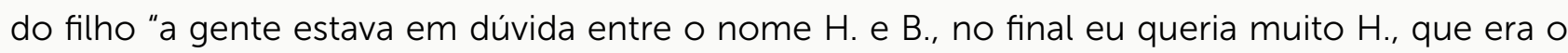
nome do meu tio avô". Já os participantes que perderam o irmão/irmã descrevem a parceria e companheirismo com o(a) irmão, como $12^{8}$ "ela [irmã do participante] tava[sic.] trabalhando com foto e eu também, era uma parceria muito legal a nossa"; e os participantes que perderam o pai/ mãe destacam o apoio dado pelos pais, como P39: "eu achava que ela tinha feito tanto por mim que eu podia estar, sei lá, em uma casa ao lado ou alguma coisa assim, a minha vida podia ser

\footnotetext{
Entrevista realizada em 29/08/2012

Entrevista realizada em 4/12/2012.

8 Entrevista realizada em 24/10/2012.

9 Entrevista realizada em 03/03/2014.
} 
tão triste".

As narrativas sobre o relacionamento no ciclo vital adulto estão intimamente articuladas ao que qualifica a identidade dos participantes (Carter e Mcgoldrick, 1995), o que significa as tarefas em que cada um estava envolvido antes do falecimento do membro familiar, como a relação conjugal, parental, fraternal e filial. Nesse sentido, a produção destas narrativas pelos participantes dá visibilidade ao processo de busca de significados, a partir destas relações. Nessa mesma direção, estão as narrativas sobre as características sobre o vínculo afetivo.

A participante $\mathrm{C}^{10}$ caracteriza o vínculo com o esposo como de segurança e proteção "a minha relação - que eu mais acreditei - que essa era mesmo, a mais alma gêmea"; a participante 12 também descreve esse aspecto, e relata o bem-estar psicológico vivido na relação com o irmão: "a gente era muito amigo [...] muito cúmplice"; a participante P3 destaca o cuidado no vínculo afetivo com a mãe "para quem eu vou perguntar as coisas agora". A participante F2 ${ }^{11}$ destaca todos esses quesitos no relacionamento com o filho "ele era tudo para mim!". Essas narrativas evidenciam o que une os pais aos seus filhos é o cuidado e o que une os filhos aos seus pais é a busca por segurança. Quanto ao vínculo entre cônjuges e irmão, esse autor destaca, igualmente, que a união está associada às necessidades de segurança e cuidada (Parkes, 2009). As narrativas sobre as características do vínculo afetivo dão visibilidade às concepções básicas do self, em termos de sentimentos de segurança, cuidado e proteção, que estavam presentes no relacionamento afetivo com quem morreu. Além disso, verifica-se que os participantes também constroem narrativas sobre a imagem da pessoa que morreu no contexto familiar e social, encontrando significado num contexto mais amplo de relacionamentos afetivos e familiares.

A participante $\mathrm{C} 2$ destaca o papel de provedor financeiro e emocional do cônjuge "ele era o carro chefe e na família dele, ele era que movimentava e na minha família também", de modo que se destacam as funções de suporte desempenhadas por ele, tanto na família de origem quanto na nuclear; já a participante F2 ressalta o apoio cognitivo dado pelo filho: "meu Deus [suspira], ele era tudo para nossa família, ele era amigo, conversava, eu conversava com ele". O participante $\mathrm{P} 1^{12}$ descreve que o pai mantinha o bom clima emocional da família "Ele nunca perdia o bom humor [...], ele sempre fazia piada, ele sempre dava um jeito das coisas ficarem num clima bom na nossa família", o que indica seu papel de suporte emocional. O participante $13^{13}$ aponta que a irmã unia os membros familiares: "ela [irmã] era uma segunda mãe, não só minha, mas de todos, muito protetora, ela sempre que via que um irmão tava[sic.] mal, ela dizia: "vem cá, vamos lá, vamos fazer isso". Nesse sentido, destaca-se o papel de apoio mútuo entre os irmãos no ciclo vital adulto, que possibilita preservar a identidade familiar, valorizando a história da família (Mccullough e Rutenberg, 1995).

As narrativas descritas nesta primeira categoria sustentam o processo de encontrar significado no relacionamento com a pessoa que morreu no ciclo vital adulto, nas características do vínculo afetivo e sobre como a pessoa que morreu era vista no contexto familiar e social.

\footnotetext{
10 Entrevista realizada em 22/08/2012.

11 Entrevista realizada em 23/05/2013.

12 Entrevista realizada em 12/09/2013.

13 Entrevista realizada em 6/11/2013.
} 
Além disso, o processo de dar significado está em concordância com o padrão comportamental de confronto com a realidade da perda, a partir do modelo do processo dual do luto, bem como com o conceito de vínculos contínuos. Assim, cada participante trouxe a relação que tinha com a pessoa que morreu como instância viva em seu interior, reafirmando as concepções básicas que norteavam a vida com quem morreu. Este processo é a porta de entrada para gestar novas narrativas e o processo de dar significado, gerando outra realidade, como a da perda, do enlutamento, da crise, do enfrentamento e da mudança. Parkes (2009, p. 48) afirma que uma nova realidade só pode ser gestada quando se mantém o vínculo: "o reconhecimento do vínculo contínuo com o morto é uma das coisas que tornam possível deixar que a pessoa se vá, simplesmente porque nunca deixaremos de tê-la aqui". Na sequência apresentam-se narrativas que tratam do processo de dar significado.

\section{Processo de dar significado}

\section{Narrativas sobre a perda}

A segunda categoria conceitual se refere às experiências associadas ao adoecimento, à terminalidade e à morte de um familiar. Observam-se narrativas sobre a trajetória dos acontecimentos que culminou com a perda. Os seis participantes que vivenciaram o adoecimento do familiar relatam experiências em torno do contato com a notícia da doença do ente querido, o que pode ser ilustrado pelo seguinte relato de $\mathrm{P} 2^{14}$ : "ele [pai] estava falando com outra pessoa, desconfiei e comecei a ouvir, quando ele desligou fui falar com ele: - pai o que está acontecendo? Me fala? - 'não tá tudo bem'". No decorrer da construção da sua história de perda, essa participante destaca que foi sua mãe que comunicou a notícia da doença e esta informação foi dada por uma ligação telefônica: "na hora eu liguei para minha mãe, - mãe vem para cá [...], e ela me contou tudo, que ele tinha câncer no intestino". Neste relato observa-se que o adoecimento do pai não foi anunciado publicamente para P2. O modo de comunicação dessa realidade indica que foram pessoas muito próximas da enlutada que se envolveram nesta tarefa (Gandini e Oliveira, 2011). No que se refere ao tratamento realizado pelo pai, P2 relata: "ele [o pai] operou o intestino e ele curou [...] fez quimio [...] ficou bem". Essa narrativa evidencia que o pai da participante P2 vivenciou uma fase crônica, o que indica que o tratamento realizado possibilitou uma estabilização do ciclo evolutivo do câncer (Rolland, 1995).

As narrativas citadas anteriormente são concernentes ao processo de dar significado à doença de seu familiar e ao tratamento realizado. Por sua vez, narrativas sobre a terminalidade configuram-se quando os participantes relatam a recidiva da doença e a iminência da morte, como referiu P2: "só que depois de uns seis meses voltou [...] começou a vir a pior parte, e ele começou a ficar mais abatido, nos últimos seis meses que ele ficou mais na cama, não reagia, não

${ }^{14}$ Entrevista realizada em 15/05/2013. 
comia". Quando fala da iminência da morte, P2 assinala "mas ao mesmo tempo eu negava muita coisa, até o último minuto, eu... não achava que ele (pai) ia morrer", o que indica um padrão de comunicação familiar fechada em torno da terminalidade (Glaser e Strauss, 1969). A participante $11^{15}$, por sua vez, descreve a iminência da morte de seu irmão e seu engajamento em atender ao pedido de sedação: "quando aconteceu dele de começar a [...] foi pedido por ele para sedar [...] era um pedido dele (irmão) também [...] quando eu cheguei lá no hospital já sedaram ele".

Estas narrativas aludem ao processo de dar significado à recidiva e iminência da morte, gerando a construção da realidade da perda antecipada. Já as narrativas sobre o dia da morte foram configuradas somente pelos participantes que vivenciaram a morte repentina do membro familiar. Estes descrevem os eventos que antecederam ao falecimento, buscando uma coerência na narração da sequência de eventos. O que pode ser demonstrado pela afirmação do participante F2: "A gente tinha almoçado na casa do meu irmão [...] ele [filho] fez questão de ir, [...] aí o telefone tocou... ele pediu para ir na cachoeira". Os participantes também narraram os eventos que se sucederam à morte, de modo que o contato com a notícia da morte repentina consiste em relevante narrativa.

A participante $\mathrm{F}^{16}$ aponta que o contato com esta notícia ocorreu à noite, sendo comunicada por um policial rodoviário federal, em uma ligação telefônica: "eu tava dormindo, daí eu atendi [...] aí eles falaram: "Você é a mãe do C. R. [filho da participante]? Aí eu falei: Sou! Aí eles falaram: - aqui é da polícia e o teu filho foi morto!". Essa narrativa explicita um jogo linguístico que banaliza a morte e retraumatiza o enlutado, pela exposição de informações sobre as circunstâncias, repentinas e violentas da morte (Kovács, 2003). A participante C2 relata o modo como foi comunicada a notícia da morte do cônjuge: "quando foi 13h horas eu e a I. [filha da participante] estávamos almoçando no shopping, daí eu recebi uma ligação das minhas amigas e da minha cunhada dizendo que eu era para voltar para casa, tipo uma desculpa". Nesse relato há um jogo linguístico de descontinuidade e (in)certeza, tendo em vista as regras implícitas quanto ao que se deve dizer ou não diante de uma morte repentina (Glaser e Strauss, 1969). As narrativas apresentadas sinalizam para uma construção da realidade de uma perda repentina, permeada por experiências em torno da comunicação da notícia da morte como momento significativo para tal construção.

As narrativas que compõem a segunda categoria conceitual apontam o processo de dar significado à trajetória de perda (adoecimento, terminalidade e morte do membro familiar). O que implicou na construção da realidade da perda e, consequentemente, o processo de dar significado à vivência do enlutamento. A próxima categoria a ser apresentada refere-se a essa temática.

\footnotetext{
15 Entrevista realizada em 05/10/2012.

16 Entrevista realizada em 08/09/2013.
} 


\section{Narrativas sobre o enlutamento}

A terceira categoria sinaliza para as experiências de sofrimento dos participantes diante da perda, apresentando sua forma de expressão: o enlutamento público e o privado. Assim, as narrativas sobre o enlutamento público se referem aos rituais coletivos de luto. A participante F2 relata desta maneira: "Aí eu fui no IML [Instituto Médico Legal], aí veio a parte de escolher a roupa, o A. [cônjuge da participante] ficou lá, aí eu vim em casa, [...] ele [filho] foi velado em casa". Nessa narrativa verifica-se uma preparação dos rituais fúnebres, o que implica, de certo modo, o envolvimento da família enlutada com essa tarefa. Os ritos do velório e sepultamento constituem momentos coletivos de compartilhamento de emoções evocadas, ajudando a tornar real a morte, a identificar amigos e familiares, a reafirmar crenças propiciam uma produção de sentido para a morte e o encaminhamento do morto para a próxima fase (Parkes, 1997).

No entanto, há narrativas sobre a desqualificação dos rituais coletivos de luto, como o relato da participante F1, que não construiu nem participou do ritual fúnebre do feto, conforme suas palavras: "só que eu não queria ter chego ao final e ter que enterrar, eu acho que é uma forma de elaborar o luto na nossa cultura, mas acho que seria bem mais difícil, eu achei que foi melhor da forma como foi" Os participantes C3, C7, P1, P2, 12, 13 também demonstram essa desqualificação, o que pode ser ilustrado pela narrativa de $C 3^{17}$ : "quando o corpo chegou, eu fui, só olhei, foi suficiente [...] não queria ficar ali, velando ele. Eu disse: - Não estou confortável aqui, na verdade, até enterrava, fechava o caixão".

Ainda quanto às narrativas sobre o enlutamento público, destaca-se a medicalização da expressão do sofrimento nos rituais coletivos de luto, como declara a participante F3: "Lá no velório eu lembro que eu chorei quando eu vi [...] chorei e aí vem um monte de gente te agarra segura, ninguém deixa tu. [...] aí te enchem de remédio, te dão remédio". Discutese que o comportamento de medicar o enlutado, além de inibir o compartilhamento público da dor da perda, pode significar que esse sofrimento é vergonhoso, de modo que deve ser intimamente vivenciado, ou discretamente expresso (Koury, 2003 e Walter, 1999). Por sua vez, essa medicalização explicita a importância do enlutamento privado na sociedade ocidental e a invisibilidade social da pessoa em luto. A experiência de sofrimento é um processo do indivíduo e deve ser vivido na intimidade de quem sofre uma perda (Koury, 2003 e Walter, 2008). Quanto a este aspecto, P2 afirma: "eu não gostava de falar com as pessoas, meus amigos, meu namorado na época, porque eu não queria que as pessoas achassem: - 'coitada, o pai dela tá morrendo e tal!' Segundo, porque as pessoas, não sei... se têm obrigação de ouvir sobre o meu sofrimento!".

Este tipo de enlutamento também emerge nas narrativas sobre os rituais personalizados de luto, que envolveram despedida individual do ente querido e expressão privada dos sentimentos (Castle e Phillips, 2003; Ramshaw, 2010). De acordo com a participante C2: "quando eles prepararam o corpo [no IML], eu entrei e falei um monte de coisas, só não me lembro o que foi o que eu falei pra ele, de uma certa forma fui me despedindo". O enlutamento privado também se refere às reações à perda no âmbito indivíduo, como as emocionais, físicas,

17 Entrevista realizada em 30/09/2013. 
comportamentais e cognitivas de sofrimento. As reações emocionais foram relatadas por todos participantes no contexto da trajetória de perda (adoecimento, terminalidade e morte), o que indica que este enlutamento ocorre neste contexto. A participante C1 ilustra as reações de choque e confusão: "eu tive uma coisa física, uma convulsão de respiração, quase entrei em um momento de muita ansiedade, como uma hiperventilação, foi um troço muito, muito, muito terrivel". O padrão comportamental denominado "ansiedade de separação" é caracterizado por reações de choque, confusão, descrença, choro, angústia, ansiedade, desespero, raiva e culpa (Bowlby, 1961).

A participante P3 relata suas reações de raiva e culpa após o enterro de sua mãe: "depois de passar essa raiva, eu comecei a me sentir muito culpada, muito, muito culpada, porque eu poderia ter feito melhor do que eu fiz quando ela estava no hospital". As reações de culpa podem ser compreendidas à luz dos acontecimentos que antecederam a morte do familiar e das relações ambivalentes que não puderam ser resolvidas antes do falecimento. Tal situação evidencia ações ou omissões, entendidas como passíveis de causar dano ao familiar (Parkes, 1996).

Há também narrativas sobre reações físicas, principalmente, nas primeiras semanas após a morte do familiar, tais como: fraqueza física, náusea, anorexia, insônia e distorção da percepção, conforme relata C3: "Nessa primeira semana eu não conseguia comer e eu emagreci, acho que 4 quilos em uma semana". F2, por sua vez, destaca: "Às vezes eu vejo vultos, eu penso que é ele [filho que morreu], às vezes quando para ônibus eu fico assim, bem aqui no bico da mesa, parada, olhando para ver se ele chega". Na perspectiva etológica, as reações físicas, como perda de apetite, são compreendidas como reações de estresse, o que significa, como reações fisiológicas acionadas, que indicam uma necessidade de vigília na maior parte do tempo, pois o mundo tornou-se um lugar inseguro para viver, pois a pessoa que morreu não está mais presente (Parkes, 1996). A distorção da percepção implica também na busca pela pessoa perdida e, assim, as informações recebidas pelos sentidos são rastreadas, em busca de sinais de quem morreu, impressões ambíguas serão interpretadas de maneira que possam encaixar-se na busca destes sinais (Bowlby, 1961 e 1998).

Da mesma forma, as narrativas quanto às reações cognitivas podem ser observadas nos relatos da maioria dos participantes, o que pode ser evidenciado na fala de P1: "e eu acho que tudo tem uma razão e a razão de ter acontecido dessa forma [...] eu meio que tento buscar um motivo para tudo isso, é um pouco confuso". A busca do por quê aquela pessoa ter morrido implica o desafio de restaurar o que foi perdido e, se possível, encaixar o acontecido em outro padrão de respostas (Gillies e Neimeyer, 2006). No que se refere às reações comportamentais, observase que os participantes que perderam filhos afastaram-se de pessoas da família e de demais relacionamentos sociais após a ocorrência da morte, como ilustra a narrativa da participante F3: "Apesar de hoje meu irmão estar separado da esposa, eu convivo assim, eu noto que eu tenho dificuldade, eu não consigo conviver com ele e meus sobrinhos". A dificuldade de convivência social e, por consequência, a necessidade de resistir às narrativas de que a perda de um filho já poderia ter sido superada (Breen e O'Connor, 2011). Essa questão também é descrita por F2: "tem gente que diz para mim: - "se ele era um filho especial porque tu sofre tanto? [...] Isso me 
afasta das pessoas".

As narrativas que compõem a terceira categoria apontam o processo de dar significado à vivência do enlutamento público e privado. Tal construção implicou na elaboração de determinadas vivências de sofrimento e sua expressão, por parte dos participantes. Por fim, estas não foram isentas de conflitos e crises, pois estes aspectos foram observados nos relatos dos participantes, conforme abordado a seguir.

\section{Narrativas sobre a crise}

A quarta categoria é concernente às experiências de crise vividas pelos participantes nos âmbitos da saúde, das crenças, nos relacionamentos sociais, na família e na condição financeira dos participantes. Para tanto, narrativas singulares destacam-se, principalmente quanto à sintomatologia física ou mental que afetou a saúde, como é ilustrado pelos participantes P1 e C2, respectivamente: "depois que ele morreu, um mês depois eu comecei a ficar doente, fisicamente, comecei a ter febre, tive herpes, tive herpes três vezes em um mês"; "eu tive um período de depressão e eu precisei medicar, porque como é que se manifestou".

Essas narrativas apontam o impacto do sofrimento pela perda de filho e do cônjuge na saúde mental, indicando que ele está associado à depressão e ansiedade (Parkes, 2009). O mesmo não pode ser afirmado, quando se trata da perda de pais na vida adulta e perda de irmãos. Para essa população ocorre um aumento na procura por serviços de atenção à saúde física, que muitas vezes não associa a sintomatologia ao evento da perda (Souza, Moura e Pedroso, 2009).

Quanto ao sistema de crenças, observam-se impactos, como o que é narrado pela participante C1: "o luto levou o meu otimismo, minha alegria, a minha confiança extrema na vida [...] o dia de sol já não tem mais o mesmo significado para mim". Essa narrativa sinaliza a condição psíquica advinda do enlutamento privado, como alteração da percepção do mundo e de si (Parkes, 2009). Esse impacto se estende aos relacionamentos sociais, como de amizade, conforme a participante I3: "amigos, eu perdi, vou te dizer sinceramente, eu perdi. Eu não tinha um amigo que eu pudesse ligar e contar, os amigos fogem do sofrimento". Esses dados indicam convergência com os estudos de Breen e O'Connor (2011), e de Koury (2003), quanto ao distanciamento e à dificuldade das redes de relacionamentos sociais no enlutamento privado, e a retirada de suporte que era conhecido e esperado. Os relatos dos participantes C3, F3, P1, P2 e C2 indicam que a condição de enlutamento, principalmente associada à perda do cônjuge, filho ou pai, é visto como pena, como declara C2: "as pessoas olham para quem ficou viúva, tipo heroína, eu olhava, e só pensava: - é, uma coisa como se fosse louvável! As pessoas olham para você como se fosse com pena".

A experiência do enlutamento também gerou crise nos relacionamentos familiares, o que pode ser ilustrado pela fala da participante F3: "sabe aquelas coisas que ficam muito marcadas, aquelas palavras não ditas? Então tem muita coisa sobre a morte da minha mãe que estão assim, não ditas". A comunicação familiar constitui um dos padrões de interação familiar mais afetado 
após a perda. Nessa direção, a perda do último genitor vivo pode significar a desintegração do núcleo familiar, e a maioria das famílias tem conhecimento dessa situação. Muitas vezes essa dissolução não é associada a padrões disfuncionais de comunicação familiar, engendrados no contexto de uma perda (Walsh e Macgoldrick, 1998).

O enlutamento também gerou crise na condição financeira, referente às pendências deixadas por quem morreu, como relata a participante C2: "ele [cônjuge] tinha há pouco comprado uma rádio e tinha vendido uma empresa e tinha muitas coisas de encaminhamento". Essa narrativa explicita os diversos encargos com os quais as participantes que perderam o cônjuge tiveram que se ocupar após a morte deste membro familiar (Parkes, 1996). O trâmite do inventário, que se seguiu algum tempo após a morte do familiar confirma os encargos pós-perda, para lidar com a situação financeira da família, conforme relata C2: "a parte que mais me decepcionou foi a forma que a justiça lidou com a situação do inventário: "documenta", "prova", "mostra" e eu justificando e as coisas que eu pedi e que me aliviaria muito". Os participantes que perderam o pai ou a mãe lidaram com a questão do testamento e da partilha de bens, de modo que é possível observar diferentes desenlaces. Segundo a participante P2: "em termos de dinheiro, o meu pai deixou um dinheiro, mas meus irmãos não abdicaram do dinheiro, o que ficou para mim e para o $P$. [irmão], e que era da vontade dele". A organização dos pertences pessoais do falecido recebeu atenção especial nas narrativas da participante que perdeu a mãe, situação que não foi isenta de questionamentos entre os membros familiares, como se observa no relato da participante P3: "o quarto da mãe ficou lá, é intocável, na casa da minha irmã, [...] mas isso deu briga entre nós".

As narrativas que compõem a quarta categoria apontam o processo de dar significado às crises na saúde, crenças, relacionamentos sociais, na família e condição financeira vividas no contexto do enlutamento público e privado. Por sua vez, tal processo implicou na construção de estratégias de enfrentamento dessas crises, tema abordado a seguir.

\section{Narrativas sobre o enfrentamento}

A quinta categoria apresenta as experiências relacionadas aos apoios buscados no contexto das crises explicitadas que, de certa forma, implicaram em lidar com a própria condição e com os efeitos de estar enlutado. Assim, narrativas singulares se destacam, como o apoio espiritual, conversas com o falecido, apoio psicológico, ocupação do trabalho e estudo, apoio da família e dos amigos. O apoio espiritual é exemplificado pela narrativa da participante F3: "eu foquei muito no lado espiritual nesse sentido assim de tu tá ajudando as pessoas, pela casa, pela motivação que eu sinto que é uma resposta que me dá para entender o modo dele morrer". Essa fala pode ser associada aos resultados da pesquisa de Koury (2003), que demonstrou que $25,86 \%$ dos enlutados declararam receber apoio da religião, de modo que construíram uma nova visão sobre o mundo e acerca da pessoa que morreu, indicado por mais de $70 \%$ dos respondentes, num total de 1.304 informantes. Já com relação às conversas com a pessoa que morreu, a participante C2 referiu que "sempre conversando com ele (cônjuge) sempre trocando, falando, desabafando, 
ele ainda é muito presente no dia a dia, eu sempre sei o que ele diria em relação aos filhos". Segundo Klass, Silvermann e Nickmann (1996), tal quadro caracteriza a manutenção de uma relação simbólica, pela imaginação em torno da maneira como a pessoa que morreu teria agido em determinados momentos.

Por outro lado, os participantes buscaram apoio psicológico, visto como um modo de socialização com pessoas que também vivenciaram sofrimento do luto, como destacam C1, C2, F1, F3, P2. Quanto a este aspecto, C1 relata: "eu acho que o primeiro ano foi terrível, aí eu fiz terapia, e eu ainda falava pouco, acho que a gente ficou um ano, no grupo de apoio. Foi uma coisa que me ajudou muito, muito, muita coisa de conviver com outras pessoas". Esse tipo de enfrentamento converge com os dados do estudo de Freire (2005), quanto à sociabilidade desenvolvida por enlutados, no contexto dos grupos de apoio oferecidos por um cemitério local.

$O$ trabalho e o estudo também passaram a constituir experiências de enfrentamento, pela possibilidade de ocupação e socialização, porém, de forma diferenciada, para afastar-se da identidade pública de enlutado, conforme pode ser constatado nas narrativas das participantes P1 e C3, respectivamente: "eu segui trabalhado, acho que o trabalho foi uma boa ocupação para mim"; "Lembro que na faculdade eles me ajudaram muito [...]. Me davam mais conforto, pois não falavam da perda". Assim, os resultados da pesquisa de Koury (2003), que apontaram que ocuparse com o trabalho foi significado pelos participantes de sua pesquisa como uma espécie de fuga do sofrimento e, também, como uma instância individualizadora, que retira o sujeito do social e empurra o sofrimento para sua interioridade. Esse aspecto pode ser observado na narrativa de C2: "eu pensava assim, quando eu entro no consultório eu preciso estar bem, pois eu vou estar cuidando de outras pessoas, então, esse espaço foi o meu verdadeiro espaço de.... saída do luto".

O apoio da família consistiu em importante referência de enfrentamento, nas palavras de C1 e F2, respectivamente: "Fiquei como mãe de outras pessoas"; "Eu vivo pela minha filha". Nessas narrativas é possível verificar a retomada de um senso de propósito da vida, por meio de novos papéis familiares e novas funções. Assim, o foco dos participantes passa a ser também a redefinição dos relacionamentos familiares, o que evidencia um padrão de enfrentamento focado na transformação do vínculo e no afastamento do confronto da realidade da perda. Essa discussão, por sua vez, é referendada por Walsh e McGoldrick (1998) e Shapiro (1994), quando demonstraram que os enlutados buscam redefinir seu relacionamento com o familiar que morreu, ao mesmo tempo em que renegociam sua identidade, num contexto familiar mudado.

O apoio dos amigos também foi referido como relevante dado, por participantes que perderam o cônjuge, como relatado por C1: "isso é outra coisa que eu vi num atendimento a uma crise, quando eu precisei, estavam todos lá [amigos]". Essa narrativa é referendada pelo estudo de Koury (2003), que aponta que os amigos representaram apenas $8,18 \%$ do apoio recebido diante do luto. Nesse sentido, esse autor demonstra que as relações de amizades, diversamente das de parentesco, são construídas sob um espectro mais individualista, o que implica numa rede de sociabilidade determinada por afinidades no campo dos valores, das crenças e dos objetivos de vida.

As narrativas que compõem a quinta categoria sustentam o processo de dar significado 
ao enfrentamento das crises, de viver a condição de estar enlutado com apoios específicos, como espiritual, conversas com a pessoa que morreu, psicológico, ocupação do trabalho e estudo, família e amigos. Ademais, o enfrentamento gerou mudanças significativas para os participantes, o que é discutido na sequência.

\section{Narrativas sobre as mudanças}

A sexta categoria é concernente às experiências quanto às mudanças positivas e negativas advindas da condição de perda, enlutamento, crise e enfrentamento. Para tanto, narrativas singulares quanto às mudanças na percepção do self podem ser observadas em C1, C2, P1, P2, 11, C3, F2, 12 e 13. Para exemplificar esta questão, apresenta-se o relato de C1: "uma forma de crescimento, uma prova, tu tem que superar de alguma forma [...] não digo sair melhor, ninguém sai melhor de uma perda tão grande, mas sai diferente". A mudança no modo de se relacionar com outra pessoa também foi descrita por F3: "eu fiquei mais sensível com a dor do outro, fiquei mais compadecida com a dor do outro [...], a gente faz um mundo, igual a perna amputada, sempre vai estar faltando aquele pedaço, mas tu aprende a conviver". Tal condição implica no aumento de conexão com os outros ou, ainda, num profundo senso de empatia. Estas mudanças implicam no que Calhoun e Tedeschi (2001) apontaram, quanto ao crescimento pós-traumático de cunho existencial e espiritual, e inclui os ganhos que podem resultar da luta com a perda.

Para os participantes F1, F2 e P3 ocorreram mudanças negativas, de modo que a morte gerou persistentemente medo, infelicidade e angústia, como pode ser observado na narrativa de P3: "pra fazer esse balanço? Olha, eu não consigo. Não vi essas mudanças positivas". A participante F2 também relata essa questão: "eu não tenho felicidade no meu coração, eu só tenho angústia". Já F1 declara: "tem muitos medos, muitos receios, de acontecer de novo, da história se repetir, medo que a gente se afaste [casal], se separe". Davis (2001) aponta que, quando há pendências quanto à circunstância de morte, as mudanças podem ser negativas. Na história de F1, observa-se que a circunstância de morte do feto gerou pendências com relação a uma nova gestação com malformação fetal. Na história de P3 há uma circunstância de morte ambígua, na qual a morte da mãe foi antecipada, devido ao uso indevido do remédio. $\mathrm{Na}$ história de F2, há uma pendência, quanto à apuração das responsabilidades do condutor da moto, sobrinho da participante.

As narrativas que compõem a sexta e última categoria sustentam o processo de dar significado às mudanças positivas na percepção do self, bem como negativas, de modo que é possível afirmar que o enfrentamento gera novos significados quanto ao self. Além disso, as categorias conceituais citadas no processo de dar significado estão associadas ao padrão comportamental de reconstrução da identidade, a partir do modelo do processo dual do luto, bem como com o conceito de vínculos contínuos, pois cada participante construiu uma realidade alternativa àquela vivida antes da perda. Assim, trata-se de uma realidade em que o 
ente querido está fisicamente ausente, mas simbolicamente presente.

\section{Conclusão}

O desafio de compreender o processo de luto a partir da teoria da reconstrução do significado implicou na compreensão de narrativas que aludem a dois processos, o de encontrar e dar significado. Deste modo, descrevem-se as narrativas que versam sobre as experiências vividas antes da morte do familiar, ao relacionamento antes da pessoa morrer, bem como as narrativas que implicam a construção da realidade da perda, do enlutamento, da crise, do enfrentamento e da mudança. Neste sentido, o processo de luto ocorre em duas direções simultaneamente, na manutenção de significados previamente consolidados, e na articulação de novos significados e possibilidades identitárias. Assim, a experiência de transformação do mundo presumido dos participantes envolveu os processos de encontrar e dar significado, na experiência narrativa de continuidade e mudança de crenças e do self.

Este artigo busca contribuir para uma mudança paradigmática quanto às possibilidades de apoio à pessoa em luto; o que implica em problematizar padrões normativos de enfrentamento de uma perda, na medida em que o processo de luto é concebido a partir da manutenção e transformação do mundo presumido. Nesse sentido, sugere-se viabilizar relações de apoio psicossocial que estimulem diálogos em torno de narrativas sobre o mundo presumido existente anteriormente à morte do membro familiar.

As narrativas dos entrevistados são referendas pela vasta literatura no campo da Psicologia do luto. Nesse sentido, os cuidados éticos referentes ao estudo da experiência de luto são reafirmados, a fim de trazer à tona a responsabilidade relacional, ao propor diálogos em torno dessa experiência. Destaca-se a necessidade de uma postura dialógica frente aos enlutados, que possibilite uma construção de narrativas como um processo relacional, na qual todos possam participar efetivamente. Neste estudo foram compartilhadas experiências em torno da vida e da morte de pessoas significativas, o que gerou ressonâncias tanto nos participantes da pesquisa quanto na pesquisadora, no que se refere às principais narrativas utilizadas para descrever as vivências de perda. Nesse sentido, referindo-se à situação de entrevista, as reflexões do pesquisador em torno dos relatos dos entrevistados consistem em produto de sua própria cultura.

É importante destacar as limitações deste estudo, pois a situação socioeconômica dos participantes, com maioria com educação universitária, limitou seu aprofundamento. Em distintos estratos sociais, os rituais e as formas de enfrentamento podem ser muito diferentes. Verifica-se a necessidade de pesquisas sobre narrativas de luto com participantes pertencentes a outros contextos sociais. 


\section{Referências Bibliográficas}

ATTIG, Tomas. Relearning the world: making and finding meanings. In: NEIMEYER, Robert (org.). Meaning reconstruction and the experience of loss. Washington: American Psychological Association, p. 33- 53, 2001.

BOWLBY, John. Processes of mourning. The International Journal of Psycho-analysis. London, $\mathrm{v}$. $13, \mathrm{n} \div .4 / 5$, p. 317-340, 1961.

Separação: angústia e raiva. São Paulo: Martins Fontes, 1998. 451p.

BREEN, Linn \& O'CONNOR, Marie. Family and social networks after bereavement experiences of support, change and isolation. Journal of Family Therapy. v. 33, p. 98-120, 2011.

CALHOUN, Logan, \& Tedeschi, Robert. Posttraumatic growth: the positive lessons of loss. In: ROBERT, Neimeyer (org). Meaning reconstruction and the experience of loss Washington: American Psychological Association, p. 157-172, 2001.

CARTER, Betty e MACGOLDRICK, Monica. As mudanças no ciclo de vida familiar: uma estrutura para a terapia familiar. $2^{\text {a }}$ ed. Porto Alegre: ARTMED, 1995. 510p.

CASTLE, John \& PHILLIPS, Willian. Grief rituals: aspects that facilitate adjustment to bereavement. Journal of loss and trauma, v. 8, p. 41- 71, 2003.

DAVIS, Carl. The tormented and transformed understanding responses to loss and trauma. In: ROBERT, Neimeyer (org.). Meaning reconstruction and the experience of loss Washington: American Psychological Association, p.137-155, 2001.

DENZIN, Norman. K. e LINCOLN, Yvonna. S. O planejamento da pesquisa qualitativa: teorias e abordagens. 2a. ed. Porto Alegre: ARTMED, 1980. 430p.

FRANCO, Maria Helena Pereira. Uma mudança de paradigma sobre o enfoque da morte do luto na contemporaneidade. In: FRANCO, Maria Helena Pereira (org.). Estudos avançados sobre o luto. São Paulo: Editora Livro Pleno, p. 15-38, 2002.

Porque estudar o luto na atualidade? In: FRANCO, Maria Helena Pereira (org.). Formação e rompimento de vínculos: o dilema das perdas na atualidade. São Paulo: Summus Editorial, p. 17-42, 2010.

FREIRE, Milena Carvalho Bezerra. O som do silêncio: isolamento e sociabilidade no trabalho de luto. Natal: EDUFRN, 2005. 188p.

GANDINI, Rosa Carla e OLIVEIRA, Luisa Todeschini Pereira. A recepção e transmissão do diagnóstico de câncer de mama na perspectiva das pacientes. In: VIII CONGRESSO DA SOCIEDADE 
BRASILEIRA DE PSICOLOGIA HOSPITALAR, São Paulo, Anais Eletrônicos, 2011. (Cd-rom)

GILLIES, Jule \& NEIMEYER, Robert. Loss, grief and the search for significance: toward a model of meaning reconstruction in bereavement. Journal of Constructivist Psychology, v. 19, p. 31-65, 2006.

GLASER, Barney \& STRAUSS, Anselm. Discovery of Grounded Theory: estrategies for qualitative research. Chicago/Nova York: Aldine De Gruyter, 1969. 369p.

GRANDESSO, Marilene. Sobre a reconstrução do significado: uma análise epistemológica e hermenêutica da prática clínica. São Paulo: Casa do Psicólogo, 2011. 248p.

GUEST, Gian; BUNCE, Aaron \& JOHNSON, Lon. How many interviews are enough? An experiment with data saturation and variability. Disponivel em: <http://journals.sagepub.com/doi/ abs/10.1177/1525822X05279903>. Acesso em: 25/02/2012.

KLASS, Dennis; SILVERMAN, Silver \& NICKMANN, Sam. Continuing bonds: new understandings of grief. Washington: Taylor and Francis, 1996. 345p.

KOURY, Mauro Guilherme Pinheiro. Sociologia da Emoção: o Brasil urbano sob a ótica do luto. Petrópolis: Editora Vozes, 2003. 215p.

KOVÁCS, Maria Júlia. Educação para a morte: temas e reflexões. São Paulo: Casa do Psicólogo, 2003. $175 p$

LUNA, Ivânia Jann e MORÉ, Carmen Leontina Ojeda Ocampo. O modo de enlutamento na contemporaneidade e o aporte do construcionismo social. Nova Perspectiva Sistêmica, Rio de Janeiro, v. 22, no. 46, p. 20-35, agosto de 2013.

LUNA, Ivânia Jann. Histórias de perdas: uma (re)leitura da experiência de luto. 2014. Tese (Doutorado em Psicologia). Programa de Pós-graduação em Psicologia, Universidade Federal de Santa Catarina, Florianópolis, 2014, 249p.

MARRIS, Peter. Loss and change. 4를 ed. London: Routledge, 1993. 329p.

MCCULLOUGH, Paul e RUTENBERG, Sam. Lançando os filhos e seguindo em frente. In: CARTER, Betty e MCGOLDRICK, Monica (orgs.). As mudanças no ciclo de vida familiar: uma estrutura para a terapia familiar. 2a ed. Porto Alegre: ARTMED, p. 248-268, 1995.

MCGOLDRICK, Monica e GERSON, Randy. Genetogramas e o ciclo de vida familiar. In. CARTER, Betty e MCGOLDRICK, Monica (orgs.). As mudanças no ciclo de vida familiar: Uma estrutura para a terapia familiar. Porto Alegre: Artes Médicas, p.144-168, 1995.

MCGOLDRICK, Monica; GERSON, Randy e PETRY, Sulivan. Genogramas: avaliação e intervenção familiar. Porto Alegre: ARTMED, 2012. 328p.

MINAYO, Maria Cecília. O desafio do conhecimento: pesquisa qualitativa em saúde. Rio de Janeiro: Hucitec-Abraco, 2010. 269p. 
MOURA, Carina. Uma avaliação da vivência do luto conforme o modo de morte. Dissertação (Mestrado em Psicologia). Programa de Pós-graduação em Psicologia do Instituto de Psicologia, Universidade de Brasília, Brasília, 2006. 180p.

MUHR, Tomas. ATLAS/ti the knowledge workbench. V 5.0 Quick tour for beginners. Berlin: Scientific Software Development, 2004. 314p.

NEIMEYER, Robert. Meaning reconstruction and the experience of loss. Washington: American Psychological Association, 2001. 423p.

; KLASS, Dennis \& DENNIS, Michael Robert. A Social Constructionist Account of Grief: Loss and the Narration of Meaning. Death Studies. v. 38, p. 485-498, 2014.

OLABUÉNAGA, José Ignacio Ruiz. Metodología de la investigación cualitativa. Bilbao: Universidad de Deusto, 2009. 289p.

PARKES, Colin Murray. Bereavement as a psychosocial transition: processes of adaptation to change. Journal of Social Issues, v. 44, no. 3, p. 53-65, 1988.

Guidelines for conducting ethical bereavement research. Death Studies, v.19, p.171-181, 1995.

Estudos sobre o luto na vida adulta. São Paulo: Summus Editorial, 1996. 214p.

Ajuda aos agonizantes e indivíduos de luto. In: Parkes, Colin Murray; Paul, Laungani \& Bill, Young (orgs.). Morte e luto através das culturas. Lisboa: Climepsi Editores, p. 239-254, 1997.

Amor e perda: as raízes do luto e suas complicações. São Paulo: Summus Editorial, 2009. 446p.

RAMSHAW, Eduard. The personalization of postmodern post-mortem ritual. Pastoral Phychology, v. 59, p.171-178, 2010.

ROLLAND, Jonh. Doença crônica e o ciclo de vida familiar. In: CARTER, Betty; MCGOLDRICK, Monica (orgs.). As mudanças no ciclo de vida familiar: uma estrutura para a terapia familiar. $2^{\underline{a}}$ ed. Porto Alegre: ARTMED, p. 373 -392, 1995.

SHAPIRO, Ester. Grief as a family process: a developmental approach to clinical practice. New York: The Guildford Press, 1994. 307p.

SLUZKI, Carlos. E. A rede social na prática sistêmica: alternativas terapêuticas. São Paulo: Casa do Psicólogo, 1997. 147p.

SOUZA, Airle Miranda; MOURA, Denise. Souza Correa e PEDROSO, Valquiria Aram Camargo. Implicações do pronto-atendimento psicológico de emergência aos que vivenciaram perdas significativas. Psicologia Ciência e Profissão, v. 29, no. 3, p. 534-543, 2009.

STRAUSS, Anselm e CORBIN, Judith. Pesquisa Qualitativa: técnicas e procedimentos para o 
desenvolvimento de teoria fundamentada. 2ª . ed. Porto Alegre: Artes Médicas, 2008. 288p.

STROEBE, Margareth \& STROEBE, Wolfgan. The symptomatology of grief. In: MARGARETH, Stroebe \& WOLFGAN, Stroebe (orgs.). Bereavement and health: the psychological and physical consequences of partner loss. Cambridge University Press, p. 7-25, 1994.

STROEBE, Margareth \& SCHUT, Henk. The dual process model of coping with bereavement: rationale and description. Death Studies, v. 23, p. 197-224, 1999.

VALENTINE, Cristine. Methodological Reflections: attending and tending to the role of the researcher in the construction of bereavement narratives. Qualitative Social Work, v. 6, n. 2, 159176, 2011.

WALSH, Froma e MCGOLDRICK, Monica. A perda e a família: uma perspectiva sistêmica. In: WALSH, Froma e MCGOLDRICK, Monica (Orgs.). Morte na família: sobrevivendo às perdas. Porto Alegre: ARTMED. p. 27-55, 1998.

WALTER, Tony. A secularização. In: PARKES, Colin Murray; LAUNGANI, Paul e YOUNG, Bill. Morte e Luto através das culturas. Lisboa: Climepsi Editores, p. 195-220, 1997.

Grief narratives: the role of medicine in the policing of grief. Anthropology \& Medicine, v. $7, \mathrm{n} \times$. 1, 97-114, 1999.

What is complicated grief? A social constructionist answer. Omega, v. 52, n. 1, p. 7179, 2006.

The new public mourning. In: MARGARETH, Stroebe; ROBERT, Hansson; HENK, Schut \& WOLFANG, Stroebe (orgs.). Handbook of bereavement research and practice advanced in theory and intervention. Washington: American Psychological Association, p. 241-262, 2008.

WAMBACH, Jordan. The grief process as a social construct. Omega, v. 6, no. 3, p. 201-211, 1985.

Recebido em: 24 de dezembro de 2016.

Aprovado em: 13 de maio de 2017. 